\title{
Introducing a new JAMS co-editor
}

\section{John Hulland ${ }^{1}$}

Published online: 1 June 2019

(C) Academy of Marketing Science 2019

The growth in the reputation and recognition of JAMS as a top academic journal in the Marketing discipline has been a pleasure for me to watch, and now a responsibility for me to manage as Editor-in-Chief. One of the major consequences of this growth in stature has been an increase in the overall number of manuscript submissions. For calendar year 2018, $J A M S$ received a total of 710 new manuscripts. As Editor-inChief, I have been solely responsible (as was Rob Palmatier before me) for initially evaluating all of these submissions, as well as managing the flow of all manuscripts (both new and revisions) that are not desk-rejected.

Although I enjoy this assignment, it is untenable in the long run. Virtually all of the other top journals in marketing have adopted a co-editorship model, and it is time for JAMS to do the same. Our Area Editors and ERB members do a fabulous job of evaluating research, identifying "diamonds in the rough", and working with authors to get the most out of their manuscripts, but they cannot provide the broader vision with which co-editors are endowed.

Starting June 1, 2019, Mark Houston (Texas Christian Uuniversity) will be joining me as JAMS Co-Editor, while I retain the responsibilities of being Editor-in-Chief. Mark will help me in managing the flow of manuscripts, including giving second opinions on all close call decisions. Equally importantly, Mark will be able to look at some broader strategic issues facing the journal that I have simply not been able to address recently, given the high submission volume.

For those who do not know Mark, he is highly respected in the field, and well-prepared to be Co-Editor. He has been an excellent AE for both JAMS and JM, has been an AMA academic leader, and is someone who believes strongly in service contribution. Mark has also published (as of December 2018) 44 refereed journal articles, include seven in JAMS, seven in $J M$, two in $J C R$, one in $J M R$, and one in Marketing Science. (Thus, like me, he has "published for the cycle" in our field!)

I am delighted to have Mark join me. We have already been working together as co-editors on the "Generalizations" special issue that will appear in JAMS next year, and he has been a terrific colleague in this regard. I greatly appreciate his experience, his passion for our field, and his dedication to making others better. These are values that I share, and I look forward to working with Mark on all aspects of managing JAMS.

Pulisher's note Springer Nature remains neutral with regard to jurisdictional claims in published maps and institutional affiliations
John Hulland

jhulland@uga.edu

1 Terry College of Business, University of Georgia, Benson Hall, C303, Athens, GA 30602, USA 